\title{
Association of Binucleate Rhizoctonia with Soybean and Mechanism of Biocontrol of Rhizoctonia solani
}

\author{
Susilo H. Poromarto, Berlin D. Nelson, and Thomas P. Freeman
}

Department of Plant Pathology, North Dakota State University, Fargo 58105.

Current address of S. H. Poromarto: Fakultas Pertanian, Universitas Sebelas Maret (UNS), JL IR Sutami 36-A, Surakarta, Indonesia. Accepted for publication 12 June 1998.

\begin{abstract}
Poromarto, S. H., Nelson, B. D., and Freeman, T. P. 1998. Association of binucleate Rhizoctonia with soybean and mechanism of biocontrol of Rhizoctonia solani. Phytopathology 88:1056-1067.

The association of binucleate Rhizoctonia (BNR) AG-K with soybean and the interaction of BNR, $R$. solani AG-4, and soybean seedlings were investigated to elucidate the mechanism of biocontrol of $R$. solani by BNR. Sixty-hour-old seedlings were inoculated and incubated in a growth chamber at $24^{\circ} \mathrm{C}$; plants were examined with light microscopy and with scanning and transmission electron microscopy at various times following inoculation. BNR grew over hypocotyls, roots, and root hairs, but only colonized epidermal cells. Hyphae of BNR appeared to attach to the epidermis and, $5.5 \mathrm{~h}$ following inoculation, began penetrating cells by means of penetration pegs without forming distinct appressoria or infection cushions. There was evidence of cuticle degradation at the point of penetration. Infection hyphae moved to adjacent epidermal cells by direct penetration of epidermal radial walls. There were epidermal and cortical cell necrosis, beginning with the fragmentation of the tonoplast and followed by the disintegration of cytoplasm, organelles, and plasma membranes. Cell necrosis was also observed in adjacent cells where there was no evidence

evidence of BNR hyphae in cortical cells. Attempted penetrations were observed, but papillae formed on the inside of cortical cell walls. Preinoculation of soybean seedlings with BNR 24 or $48 \mathrm{~h}$ before inoculation with $R$. solani ( $1 \mathrm{~cm}$ between inocula) affected the growth of $R$. solani on soybean tissue. There were fewer hyphae of $R$. solani, the hyphae branched sparingly, and infection cushions were rare when compared with hyphal growth on soybean inoculated only with $R$. solani. These effects were observed before the BNR hyphae began to intermingle with the hyphae of $R$. solani on the surface of the inoculated host. Preinoculation of soybean seedlings $24 \mathrm{~h}$ before inoculation with $R$. solani significantly $(P=0.05)$ reduced disease incidence and severity caused by $R$. solani AG- 4 . The lesions caused by $R$. solani always appeared distally, not proximally, to the BNR inoculum. The interactions of intermingling hyphae of BNR and $R$. solani were examined in vitro and on the surface of the host. There was no evidence of lysis, mycoparasitism, inhibition of growth, or any other form of antagonism between hyphae. The results of these studies strongly suggest that induced resistance is the mechanism of biocontrol of $R$. solani on soybean by BNR. The inhibition of hyphal growth of $R$. solani on the surface of soybean tissue preinoculated with BNR appears to be a novel characteristic of induced resistance.
\end{abstract} of BNR hyphae. Cell walls were not destroyed. After $144 \mathrm{~h}$, there was no
Binucleate Rhizoctonia (BNR) have demonstrated control of $R$. solani Kühn on various crops under both controlled environment and field conditions $(5,14,19,27,36,43)$. The nature of the association between BNR and the plant, and the mechanism of biocontrol, however, have not been adequately studied and, thus, remain poorly understood. Researchers have suggested that the mechanism of biocontrol may be due to competition for nutrients or induced host resistance $(4,6,13,20)$. Neither mycoparasitism nor antibiosis appear to be the primary mechanism of biocontrol by BNR $(4,6,27,36)$.

Cardoso and Echandi (6) demonstrated that hyphal growth and sclerotial germination of $R$. solani were inhibited in vitro by root exudates from 10-day-old, BNR-treated bean seedlings. They also demonstrated that protection against $R$. solani was still maintained after bean roots and hypocotyls were surface-sterilized with either sodium hypochlorite or ethanol to eradicate the BNR. Furthermore, BNR colonized the rhizoplane and epidermal cells, but did not penetrate beyond the epidermal cells.

Jabaji-Hare et al. (22) examined the association between BNR and bean seedlings using electron microscopy. They observed an electron-dense material associated with the walls of epidermal cells colonized by BNR, but not with epidermal tissue infected by $R$. solani. Hare et al. (18) and Xue et al. (41) reported that there were higher peroxidase and other enzymatic activity in bean plants treated

Corresponding author: B. D. Nelson; E-mail address: bernelso@plains.nodak.edu

Publication no. P-1998-0724-01R

(C) 1998 The American Phytopathological Society with BNR compared with plants not treated. They also reported that disease severity of $R$. solani was negatively correlated with increased peroxidase activity. These observations by the aforementioned researchers support the hypothesis that BNR suppress $R$. solani through induced host resistance.

The overall aim of this research was to understand the mechanism of biocontrol of $R$. solani on soybean by BNR. The objectives were to examine the association between BNR and soybean roots and hypocotyls using light and electron microscopy at various times following inoculation and to examine the interaction of BNR and $R$. solani on the surface of soybean seedlings.

\section{MATERIALS AND METHODS}

Fungal isolates, host, and inoculations. BNR AG-K isolates 8-2, 8-3, and 4, R. solani AG-4 isolate 85-1, and soybeans (cv. Ozzie) were used in this research. The BNR isolates were selected based on their ability to increase emergence and survival of soybean and to reduce the severity of damping-off and root rot caused by $R$. solani AG-4 and AG-2-2 (27). These fungi originally were isolated from soybean roots and were maintained in cryogenic storage at $-80^{\circ} \mathrm{C}$ on barley grains (33). $R$. solani AG-4 isolate 85-1 is virulent on soybean (32). To initiate growth of BNR or R. solani, frozen grains were placed directly onto potato dextrose agar (PDA) (Difco Laboratories, Detroit) at $23^{\circ} \mathrm{C}$. All experiments were initiated using stock cultures from cryogenic storage.

Tissue paper (three $10 \times 70$-mm sheets per plate) was placed in $10 \times 90$-mm glass petri plates, enriched with $7 \mathrm{ml}$ per plate of a 
$10 \%$ solution of Difco nutrient broth (Difco Laboratories), and autoclaved. Agar strips $(40 \times 5 \mathrm{~mm})$ with mycelium of BNR or $R$. solani from 3- to 4-day-old cultures on PDA were placed on the nutrientenriched tissue paper and incubated in the dark for 3 to 4 days at $23^{\circ} \mathrm{C}$. The mycelium on this paper was used as inoculum.

Soybean seeds were surface-treated with $1.0 \% \mathrm{NaOCl}$ for $45 \mathrm{~s}$, washed with sterile water, and then germinated on sterile wet filter paper in $20 \times 90$-mm petri dishes (one to two seeds per plate) at $23^{\circ} \mathrm{C}$ in a growth chamber without light. All germinating seeds contaminated with fungi were discarded. Inoculations were conducted when hypocotyls were approximately $3 \mathrm{~cm}$ long, about $60 \mathrm{~h}$ after germination. Paper strips (3 to $10 \mathrm{~mm}$ ) with mycelium were wrapped tightly around hypocotyls or roots, and plants were incubated at $23^{\circ} \mathrm{C}$ in the dark. High humidity was maintained in the petri dishes by adding $5 \mathrm{ml}$ of sterile water.
Interaction of BNR with soybean. The interaction of BNR and soybean was observed using light microscopy, scanning electron microscopy (SEM), and transmission electron microscopy (TEM). BNR isolate 8-3 was observed with all three methods, while BNR isolates 8-2 and 4 were only observed with light microscopy. For light microscopy, hypocotyls and roots were cleared in a lactophenol solution (phenol crystals/lactic acid/glycerin, 1:1:1 [wt/wt]) for 3 to 4 days, stained in $0.1 \%$ aniline blue in lactophenol for 2 to $3 \mathrm{~min}$ at $70^{\circ} \mathrm{C}$, and destained in lactophenol (8). Longitudinal sections of the epidermal area were cut with a razor blade, and sections were mounted in lactophenol. Samples were examined at 5.5, 8, $12,24,48,72$, and $144 \mathrm{~h}$ following inoculation. A Leitz Wetzlar Dialux (E. Leitz, Inc., Rockleigh, NJ) and an AO One Ten microscope (American Optical, Buffalo, NY) at $\times 100$ to $\times 1,000$ were used to observe and photograph interactions between BNR and
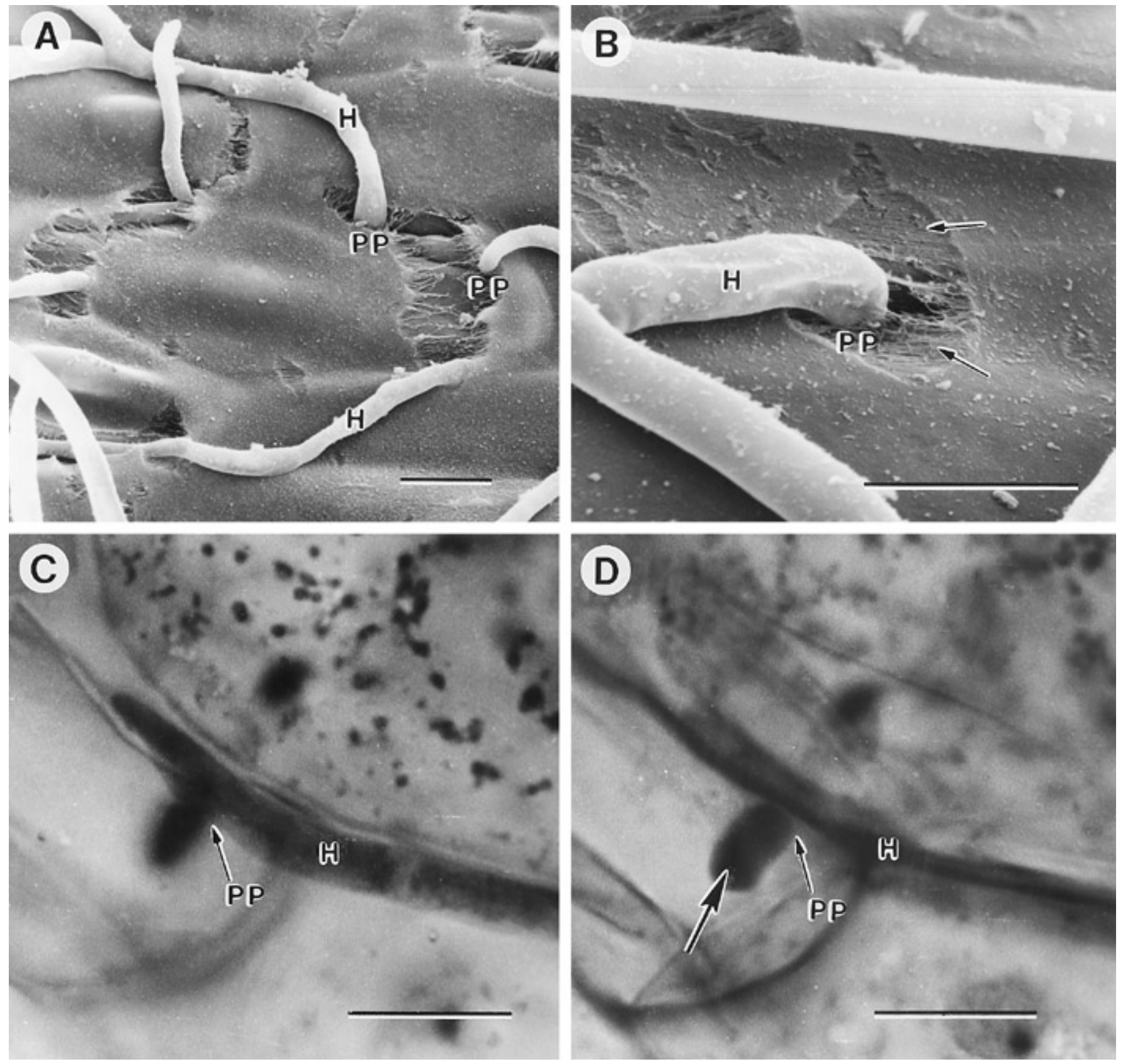

Fig. 1. Infection of soybean hypocotyls by binucleate Rhizoctonia AG-K isolate 8-3. A and B, Scanning electron micrographs and C and D, light microscopy, at $5.5 \mathrm{~h}$ after inoculation. A, Numerous infection hyphae on the surface of the hypocotyl $(\times 1,142)$. B, Penetration point showing the enzymatic degradation of cuticle (arrows) $(\times 3,142)$. C and D, Photos of the same infection hypha $(\times 2,285)$. C, The infection hypha on the surface of the hypocotyl is in focus. D, The intracellular portion of the infection hypha is in focus (bold arrow). Note the absence of specialized infection structures such as appressoria. $\mathrm{H}=$ hypha, and $\mathrm{PP}=$ penetration point. Bar $=10 \mu \mathrm{m}$. 
host tissue. Photographs were taken using Kodak TMAX blackand-white film (100 ASA) (Kodak, Rochester, NY). The observations were conducted on 10 replications per treatment, and the experiment was repeated three times.

For SEM, tissues were collected $72 \mathrm{~h}$ after inoculation and fixed

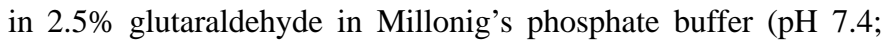
Tousimis Research Corp., Rockville, MD), dehydrated through a graded ethyl alcohol series, and critical point-dried with $\mathrm{CO}_{2}$ as a transitional fluid. Tissues were sputter-coated with AuPd (Balzers, Hudson, NH) and examined with a JEOL JSM 6300 scanning electron microscope (JEOL, Ltd., Peabody, MA). Photographs were taken using Polaroid P/N 55 or Polaroid polapan 100 film (Polaroid Corp., Cambridge, MA). For SEM, 12 inoculated seedling were observed over three separate observation periods, and at least 100 total infection sites were observed. For TEM, tissues were collected 72 and $144 \mathrm{~h}$ after inoculation, fixed in $2.5 \%$ glutaraldehyde in Millonig's phosphate buffer ( $\mathrm{pH} 7.4$ ), postfixed in buffered $2 \%$ osmium tetroxide, dehydrated in acetone, embedded in epoxy resin, and ultra-thin-sectioned. Sections were stained with lead citrate, examined, and photographed using a JEOL JEM $100 \mathrm{CX}$ electron microscope (JEOL, Ltd.). Photographs were taken using Kodak 4489 black-and-white film (Kodak). For TEM, six inoculated hypocotyls and roots per time period were sectioned and examined. Approximately 30 to 50 infected cells per sample were examined for interactions between BNR and soybean. Examinations with TEM were repeated once.

Interaction of BNR and $R$. solani in vitro and growth alone on soybean. BNR isolate $8-3$ and $R$. solani AG-4 isolate $85-1$ were grown in dual culture on PDA in $10 \times 90-\mathrm{mm}$ petri dishes and incubated at $23^{\circ} \mathrm{C}$ in a growth chamber. Agar plugs with mycelium were placed $3 \mathrm{~cm}$ apart. Dual cultures were observed daily until 5 days after hyphae began to intermingle. The interaction of the hyphae was examined with light microscopy. The mycelia were stained with $0.1 \%$ aniline blue in lactophenol and examined at $\times 100$ to $\times 1,000$ with the AO One Ten microscope. Six pairings were evaluated, and the evaluation was repeated three times.

Hypocotyls and roots of soybean seedlings were inoculated separately with BNR isolate 8-3 and $R$. solani at $60 \mathrm{~h}$ after seed germination, and the growth patterns of the hyphae were examined $24 \mathrm{~h}$ after inoculation. Hyphae were stained with $0.1 \%$ safranin and examined at $\times 100$ to $\times 1,000$. Photographs were taken at $\times 140$ using the Olympus SZH dissecting scope (Olympus America Inc., Melville, NY). Ten samples of each treatment were observed, and the experiment was repeated twice.

Effects of BNR on disease caused by $R$. solani. Soybeans were germinated and hypocotyls were inoculated with BNR isolate 8-3 as previously described. Twenty-four hours after inoculation with BNR, hypocotyls were inoculated toward the cotyledons with $R$. solani AG-4 at $0,0.5$, and $1 \mathrm{~cm}$ from the BNR inoculum. The controls consisted of hypocotyls inoculated with BNR and $R$. solani alone. Disease incidence was assessed indirectly at 5 days after inoculation with $R$. solani by counting the number of healthy seedlings. A healthy seedling had no Rhizoctonia-like lesions on the hypocotyls or roots. Disease severity was assessed on the basis of infected seedlings using a 0 to 5 scale, in which $0=$ no disease; $1=$ one lesion $<1 \mathrm{~mm}$ in diameter or $<20 \%$ girdling; $2=$ one lesion 1 to $2 \mathrm{~mm}$ in diameter, two or more lesions $<1 \mathrm{~mm}$ in diameter, or 20 to $40 \%$ girdling; $3=$ one lesion 2 to $3 \mathrm{~mm}$ in diameter, two to three
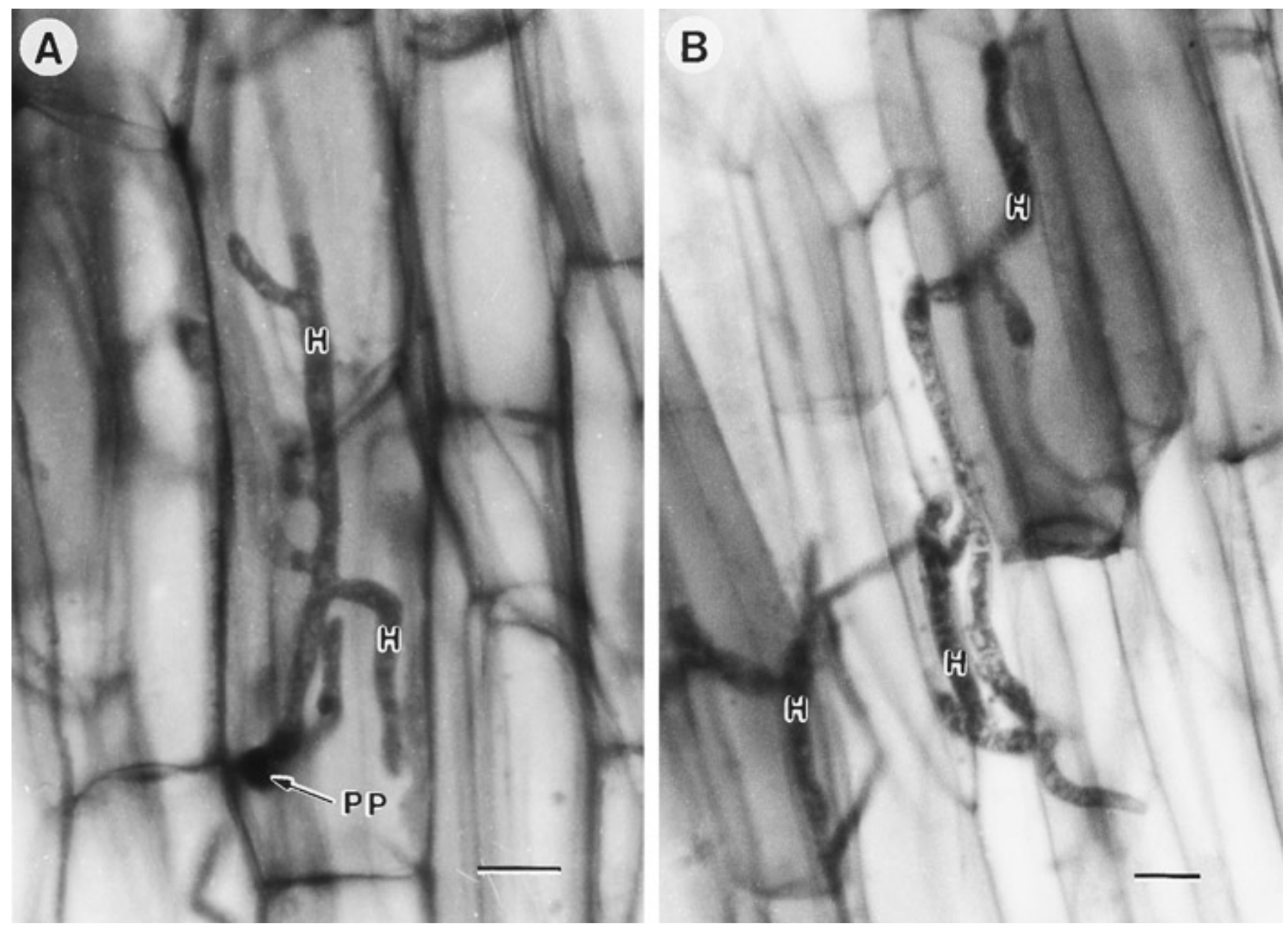

Fig. 2. Intracellular hyphae of binucleate Rhizoctonia AG-K isolate 8-3 in soybean epidermal cells $\mathbf{A}, 24 \mathrm{~h}(\times 1,142)$ and $\mathbf{B}, 72 \mathrm{~h}(\times 875)$ after inoculation. Notice branching of hyphae and development of a network of intracellular hyphae within the epidermal cell layer. The penetration point is visible in $\mathbf{A}$, but in $\mathbf{B}$, it is outside the viewing area. $\mathrm{H}=$ hyphae, and $\mathrm{PP}=$ penetration point. $\mathrm{Bar}=10 \mu \mathrm{m}$. 
lesions 1 to $2 \mathrm{~mm}$ in diameter, or 40 to $60 \%$ girdling; $4=$ two to three lesions 2 to $3 \mathrm{~mm}$ in diameter, more than three lesions 1 to $2 \mathrm{~mm}$ in diameter, or 60 to $80 \%$ girdling; and $5=$ more than three lesions 2 to $3 \mathrm{~mm}$ in diameter, 80 to $100 \%$ girdling, or death. The experiment was a completely random design with 15 subsamples per treatment and was repeated twice.

Because BNR did not cause lesions, the data from seedlings inoculated with BNR alone contained all zeros both for disease incidence and severity. Such data could not be analyzed statistically. Therefore, to assess disease incidence, the number of healthy plants was analyzed, because each of the five treatments had healthy plants. In the statistical analysis of disease severity, the data from the treatment with BNR alone were removed. The number of healthy plants and disease severity were compared by an analysis of variance (ANOVA). Treatment means were compared by Fisher's protected least significant difference test.

Growth and interactions of BNR with $R$. solani on soybean. The growth patterns of hyphae of BNR isolate 8-3 and $R$. solani on soybean seedlings when coinoculated were examined. There was $1 \mathrm{~cm}$ between the BNR and $R$. solani inocula. Inoculations with $R$. solani on cotyledons and roots were conducted at 0,24 , and $48 \mathrm{~h}$ following inoculation with BNR. Observations were made at 12 , 24 , and $48 \mathrm{~h}$ following inoculation with $R$. solani. Controls consisted of seedlings inoculated with $\mathrm{BNR}$ and $R$. solani alone. Mycelia were stained directly with $0.1 \%$ aniline blue in lactophenol or $1 \%$ safranin for 1 min and examined with the compound microscopes and an Olympus SZH dissecting scope at $\times 10$ to $\times 140$. Examinations were conducted using 15 samples per treatment. The experiment was repeated three times. Lesion formation on these samples was recorded, but severity was not determined. In addition to light microscopy, some samples were examined with SEM. Hypocotyls were inoculated first with BNR and then $48 \mathrm{~h}$ later with $R$. solani. After $48 \mathrm{~h}$ of growth of $R$. solani, seven samples per treatment, chosen at random, were fixed and prepared for SEM as previously described.

The interactions of hyphae were examined on hypocotyls inoculated at the same time with BNR isolate $8-3$ and $R$. solani, with 0.5 to $0.7 \mathrm{~cm}$ between inocula. Examinations started about $24 \mathrm{~h}$ after inoculation, when mycelia began to intermingle, and continued over $48 \mathrm{~h}$. Mycelia were stained and examined with the compound microscope. Interactions were examined on 15 inoculated seedlings per period, and the experiment was repeated three times.

The growth of $R$. solani on the surface of hypocotyls with and without preinoculation with BNR isolate 8-3 was quantified with the following method. Hypocotyls were inoculated with BNR using the previously described methods and then again $48 \mathrm{~h}$ later with $R$. solani $1 \mathrm{~cm}$ from the BNR inoculum. After $24 \mathrm{~h}$ of growth of $R$. solani, hypocotyls were stained for $1 \mathrm{~min}$ with $1 \%$ safranin and viewed at $\times 140$ using the Olympus SZH dissecting scope. The eyepiece micrometer scale was placed at 2 and $4 \mathrm{~mm}$ from the edge of the $R$. solani inoculum on the side toward the BNR, and the number of hyphae that intersected the scale was determined on one side of the hypocotyl. Each experiment consisted of two treatments (BNR $+R$. solani and $R$. solani alone), six inoculated hypocotyls per treatment, and the experiment was repeated twice. The data from each experiment was analyzed by ANOVA, and differences in sample means were tested by the $F$ ratios.

\section{RESULTS}

Interaction of BNR with soybean. Observations with SEM showed that some hyphae of BNR isolate 8-3 were tightly appressed or appeared attached to the epidermis (Fig. 1A to D). Hyphae directly penetrated epidermal cells without forming distinct appressoria or infection cushions typical of $R$. solani (Fig. 1A to D). On the surface of the host at the point of penetration, infection hyphae were often slightly swollen. Examination with SEM revealed degradation of the cuticle around the points of penetration
(Fig. 1A and B). No degradation of the cuticle was observed in the absence of BNR. Some infection hyphae entered through stomatal openings and penetrated the sides of epidermal cells.

All three isolates of BNR began penetration of epidermal cells within $5.5 \mathrm{~h}$ following inoculation and, within $8 \mathrm{~h}$, hyphae were visible within cells (Fig. 1D). BNR isolate 8-2 grew faster than BNR isolates 8-3 and 4, and within $8 \mathrm{~h}$ after infection of the epidermal cell, BNR isolate 8-2 had penetrated and established hyphae in adjacent epidermal cells. The latter two isolates required about $12 \mathrm{~h}$ to move to adjacent epidermal cells. Within $24 \mathrm{~h}$, hyphae of all three isolates of BNR had branched within cells and penetrated up to four epidermal cells distant from the primary infected epidermal cell (Fig. 2A). Within $72 \mathrm{~h}$ after infection, BNR had established an extensive network of hyphae (Fig. 2B). The aniline blue staining procedure readily stained hyphae on and in host tissue.

Hyphae of all three isolates of BNR were still observed (with light microscopy) inside the epidermal cells directly under the inoculum $144 \mathrm{~h}$ after inoculation. However, most of the hyphae did not stain or stained poorly with aniline blue and, therefore, were difficult to observe. There appeared to be fewer intact hyphae in epidermal cells at $144 \mathrm{~h}$ than at $72 \mathrm{~h}$ after inoculation. On the surface of the hypocotyls, hyphae continued to stain well with aniline blue after $144 \mathrm{~h}$, but the branching of hyphae appeared less than at $72 \mathrm{~h}$, and hyphae did not appear appressed to the epidermis.

Examination with TEM of uninoculated soybean tissue showed that epidermal and outer cortical cells were highly vacuolated with a thin layer of cytoplasm containing normal cell organelles appressed to the cell wall (Fig. 3). Infection hyphae penetrated the epidermis by a penetration peg about $0.8 \mu \mathrm{m}$ in diameter (Fig. 4A and $\mathrm{B})$. Once through the epidermal cell wall, the penetration peg enlarged about four to five times to form an intracellular hypha (Fig. 4A and B). In some penetrations, the cytoplasm of the infection hypha moved into the intracellular hypha, and a septum was

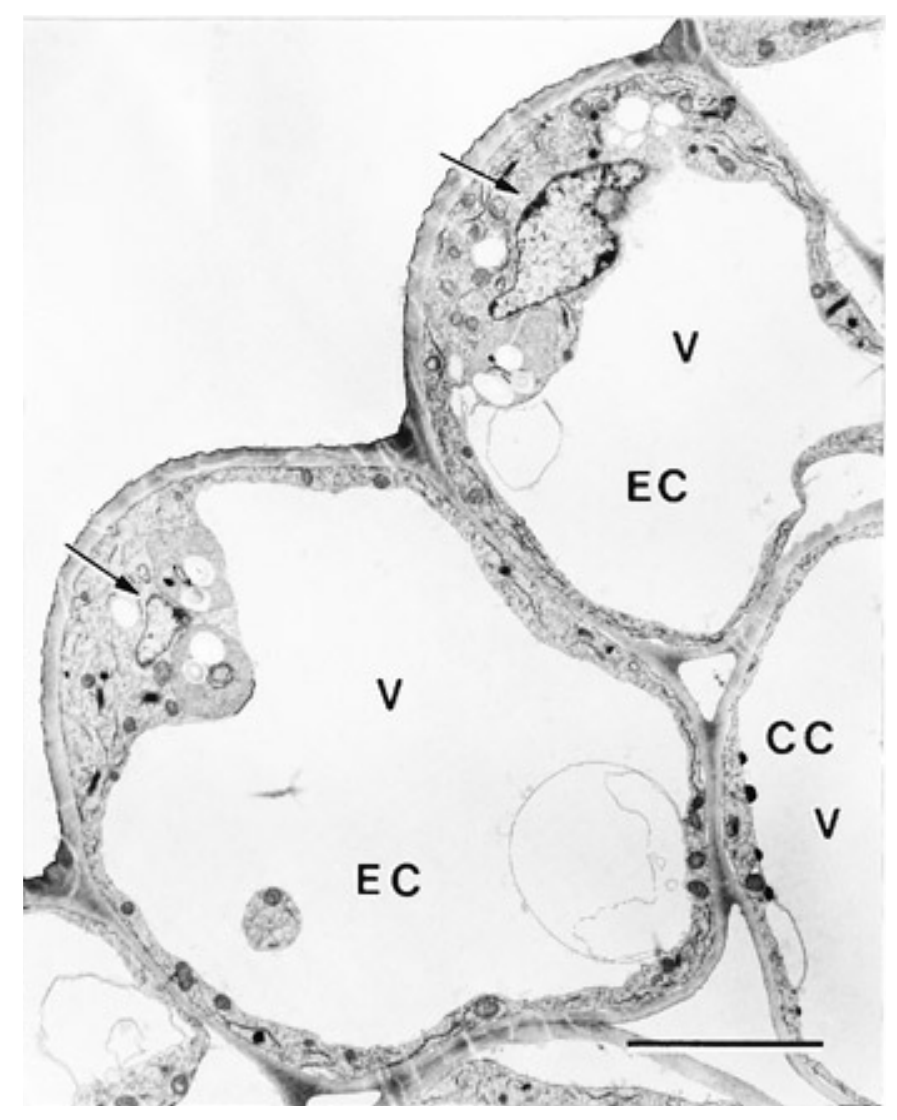

Fig. 3. Transmission electron micrograph of a soybean hypocotyl showing healthy epidermal cells $(\times 3,900)$. Notice large vacuole and layer of cytoplasm (arrows) containing normal cell organelles. Exterior wall of epidermis is on the left. $\mathrm{EC}=$ epidermal cell, $\mathrm{CC}=$ cortical cell, and $\mathrm{V}=$ vacuole. $\mathrm{Bar}=5 \mu \mathrm{m}$. 

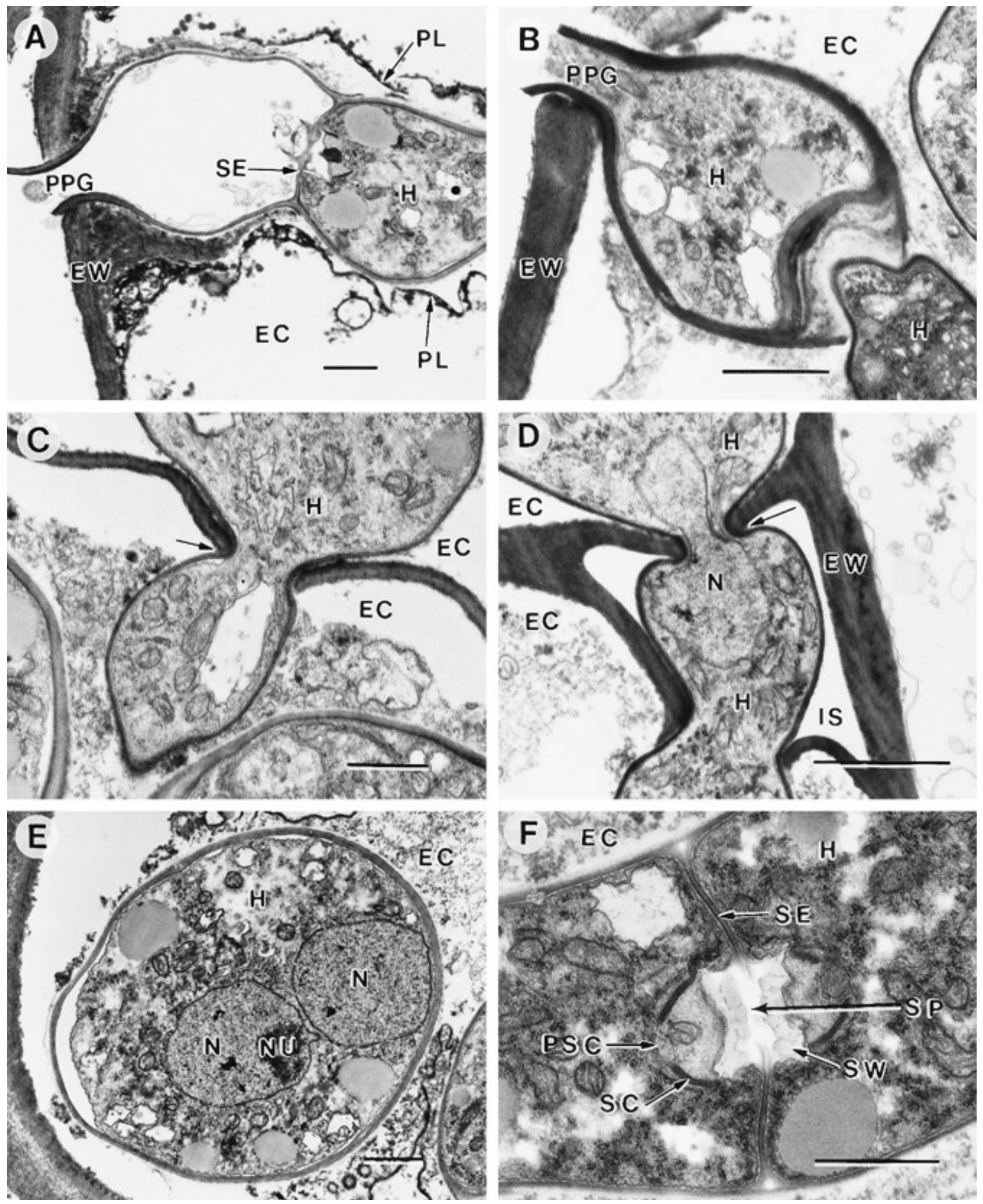

Fig. 4. Transmission electron micrographs of penetration of soybean hypocotyl epidermal cells by binucleate Rhizoctonia AG-K isolate 8-3 and subsequent growth of intracellular hyphae. A, Penetration peg in which the cytoplasm has moved into the intracellular hypha, and a septum formed near the penetration peg. Notice the invagination of the plasmalemma by the penetration peg and developing intracellular hypha and the disintegration of the plasmalemma $(\times 10,140)$. B, Penetration peg with cytoplasm and a developing intracellular hypha $(\times 19,140)$. A and B, Notice the necrosis of host cytoplasm. C, Direct penetration by intracellular hypha into adjacent epidermal cell $(\times 14,500)$. D, Penetration into intercellular space and then into another epidermal cell. Notice migration of nucleus through the penetration point; movement is from top to bottom $(\times 25,740)$. C and $\mathbf{D}$, Notice the constriction of hyphae and invagination of the epidermal side walls at the edges of the penetration sites (arrows). E, Binucleate condition of intracellular hypha ( $\times 9,960)$. F, Intracellular hypha with dolipore septum $(\times 23,500)$. EW = Epidermal cell wall, $\mathrm{H}=$ intracellular hypha, $\mathrm{EC}=$ epidermal cell, $\mathrm{PPG}=$ penetration peg, $\mathrm{PL}=$ plasmalemma, IS $=$ intercellular space, $\mathrm{N}=$ nucleus, $\mathrm{NU}=$ nucleolus, $\mathrm{PSC}=$ pore in septal pore cap, $\mathrm{SC}=$ septal pore cap, $\mathrm{SE}=$ septum, $\mathrm{SP}=$ septal pore, and $\mathrm{SW}=$ septal swelling. $\mathrm{Bar}=1.0 \mu \mathrm{m}$. 
laid down near the site of penetration, leaving an empty penetration peg and infection hypha on the epidermis (Fig. 4A). The intracellular hyphae readily spread by penetration pegs to adjacent epidermal cells or intercellular spaces (Fig. 4C and D). The force of the penetration pegs caused distortions in the radial walls such that the walls appeared to invaginate at the edges of the penetrations. Hyphae were sharply constricted when passing through these side walls (Fig. 4C and D). The movement of fungal cell organelles such as nuclei through hyphae that penetrated epidermal cell walls was observed (Fig. 4D). The binucleate condition and dolipore septa were observed in intracellular hyphae, as were numerous mitochondria and other organelles (Fig. 4E and F).

There was no evidence of hyphae of BNR isolate 8-3 in cortical cells at 72 or $144 \mathrm{~h}$ after inoculation (Fig. 5). Attempted penetrations were observed, but papillae developed on the inside of cortical cell walls (Fig. 6A to C). Papillae were frequently observed in the TEM preparations and averaged 0.8 to $0.9 \mu \mathrm{m}$ in depth. Papillae were never observed on any epidermal cell walls.

In the inoculated tissue, there were epidermal and cortical cell necrosis, beginning with the fragmentation of the tonoplast and followed by the disintegration of the plasma membrane, cytoplasm, and organelles (Figs. 4 and 5). In some penetrations, the host cell plasmalemma was pushed back by the developing intracellular hyphae, but eventually this membrane was penetrated (Fig. 4A and B). By $72 \mathrm{~h}$ following infection, some cells appeared to lose all cytoplasm. Cell necrosis was evident in infected epidermal cells and in adjacent epidermal cells where there was no definitive evidence of fungal penetration. Necrosis of cortical cells was observed only in the first two to four layers of cells below the epidermis (Fig. 5). There was no evidence of cell wall degradation, other than at the points of penetration of epidermal cells. Visual inspection of hypocotyls and roots up to $144 \mathrm{~h}$ after inoculation revealed no macroscopic evidence of soybean tissue degradation caused by BNR isolate 8-3.

Interaction of BNR and $R$. solani in vitro and growth alone on soybean. In dual cultures on PDA, there was no barrage effect when the two mycelia made contact. Mycelia of BNR and $R$. solani grew in close contact with free intermingling of hyphae. A total of 389 hyphal contacts between BNR and $R$. solani were carefully evaluated over four separate observation periods. There was no evidence of lysis, hyperparasitism, inhibition of growth, or other forms of antagonism between these two fungi.

$R$. solani had a distinctly different growth pattern from BNR on soybean. The highly branched hyphae of $R$. solani appeared to form a net over the surface of the host (Fig. 7A) and also produced infection cushions. The hyphae of BNR did not branch as extensively, did not form the netlike growth over the host, and did not form infection cushions (Fig. 7B).

Effects of BNR on disease caused by $R$. solani. Five days after inoculation of soybean, $R$. solani applied alone caused $50 \%$ disease incidence, while BNR isolate 8-3 applied alone caused no disease (Table 1$)$. There were no significant $(P=0.05)$ differences in the mean number of healthy plants between the plants inoculated with $R$. solani alone and those inoculated at 0.5 and $1 \mathrm{~cm}$ from the BNR inoculum (which was on the plant $24 \mathrm{~h}$ before $R$. solani). However, there were significantly $(P=0.05)$ more healthy plants (41\% more) when the inoculum of $R$. solani was placed directly adjacent $(0 \mathrm{~cm})$ to the BNR inoculum as compared with plants inoculated with $R$. solani alone (Table 1). Inoculation with $R$.
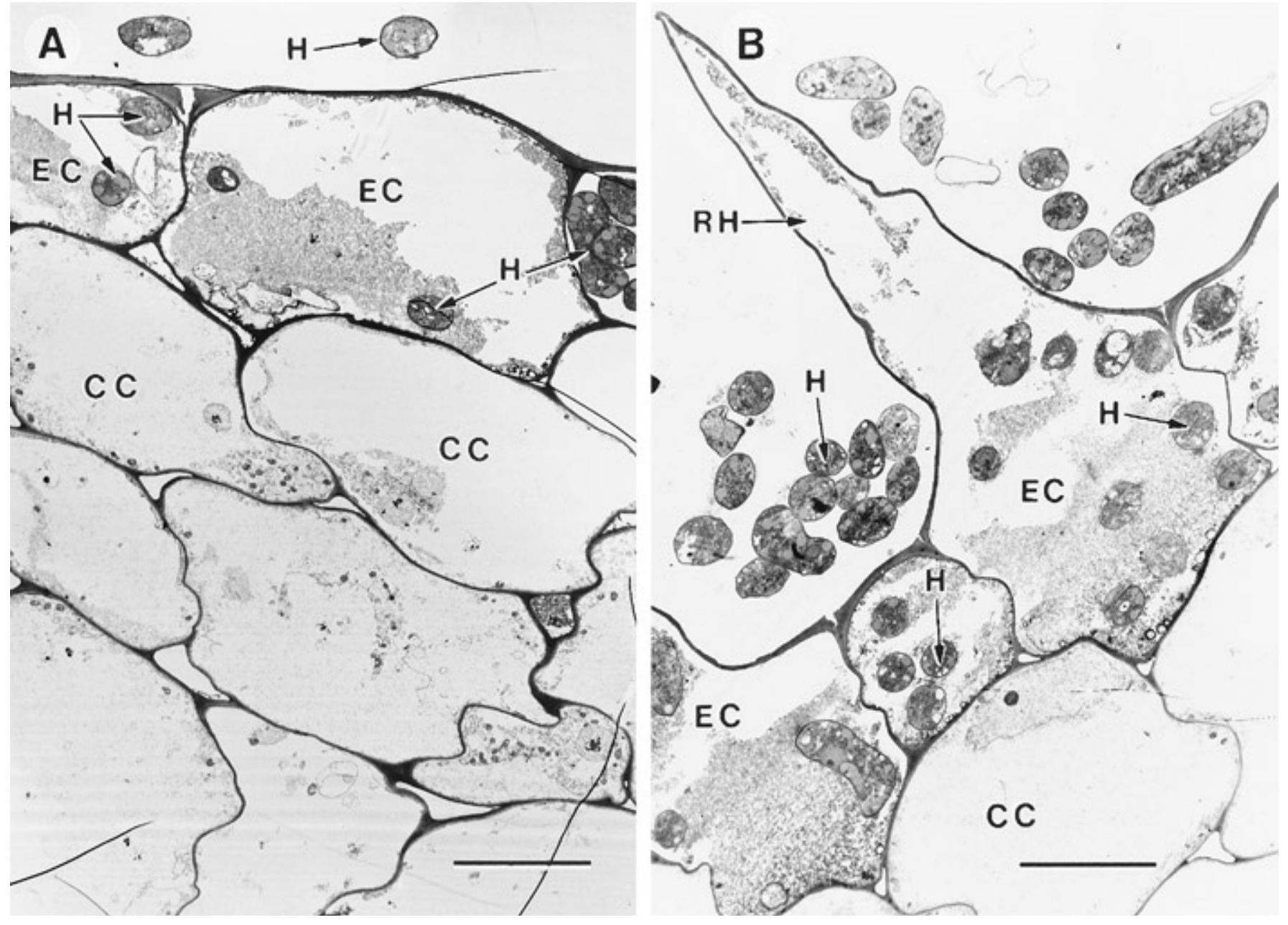

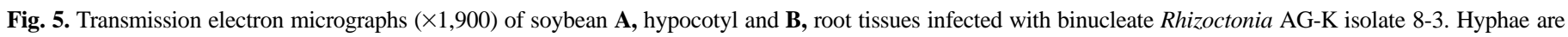

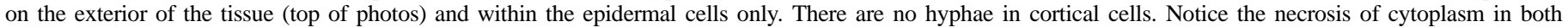
epidermal cells and cortical cells compared with the healthy tissue in Figure $3 . \mathrm{EC}=$ epidermal cell, $\mathrm{CC}=\mathrm{cortical}$ cell, $\mathrm{RH}=$ root hair, and $\mathrm{H}=\mathrm{hypha}$. Bar $=10 \mu \mathrm{m}$. 
solani at $0,0.5$, and $1 \mathrm{~cm}$ from the BNR inoculum resulted in significantly $(P=0.05)$ lower disease severities compared with inoculation with $R$. solani alone (Table 1). At $0 \mathrm{~cm}$, disease severity was reduced by $47 \%$, while at 0.5 and $1 \mathrm{~cm}$, it was $33 \%$ when compared with inoculations with $R$. solani alone.

Growth and interactions of BNR with $R$. solani on soybean. Growth patterns were observed on both sides of the inoculum strip. At 12,24 , and $48 \mathrm{~h}$ following inoculation with $R$. solani, there were no apparent differences in the growth patterns of $R$. solani on hypocotyls or roots that were inoculated at the same time with BNR isolate 8-3 when compared with tissue inoculated with $R$. solani alone. However, when inoculation of $R$. solani occurred after BNR had grown on tissue for $48 \mathrm{~h}$, there was a dramatic difference in the growth pattern on the side of the inoculum facing the BNR as compared with that observed on the side of the $R$. solani inoculum away from the BNR or on tissue inoculated with
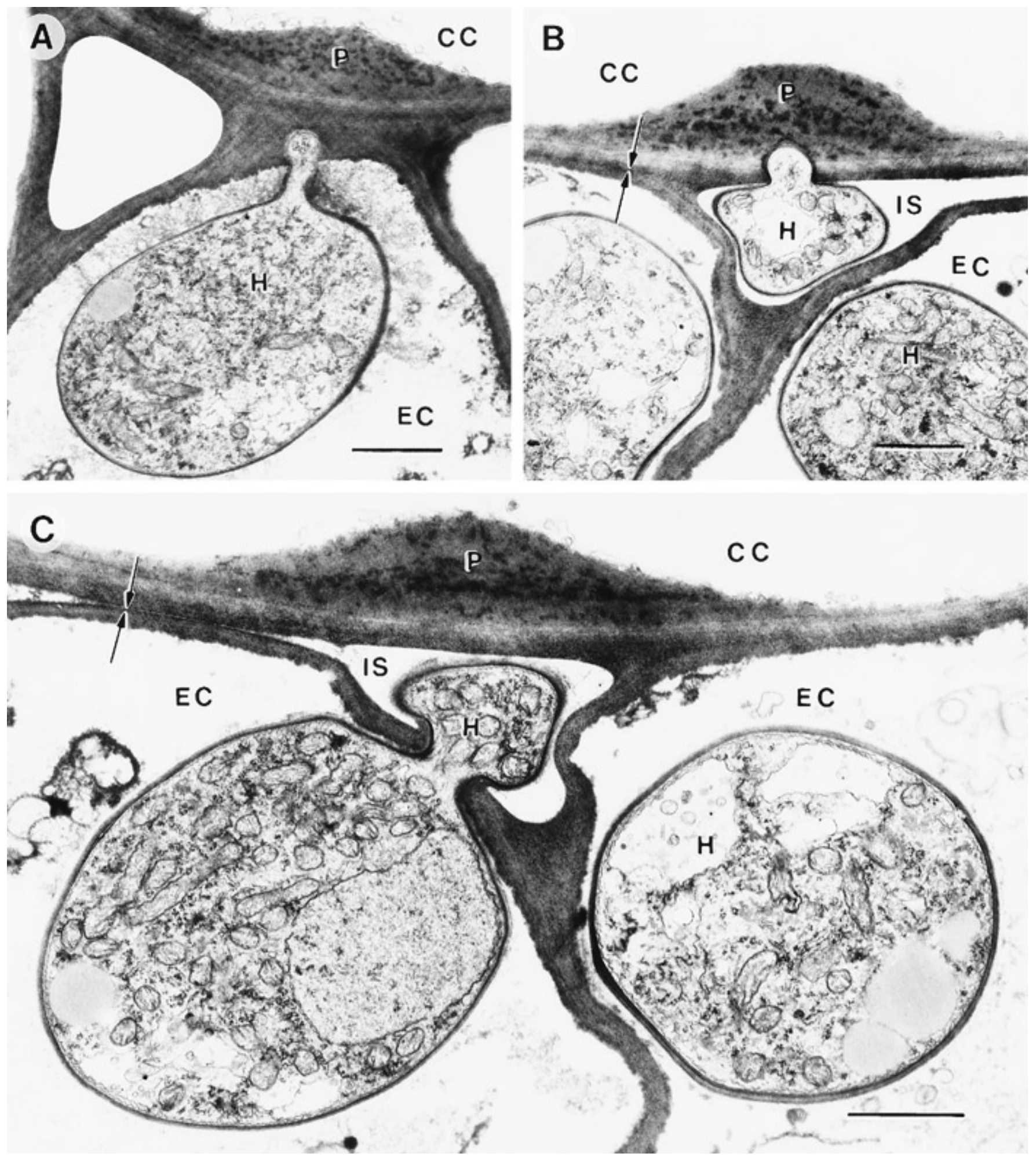

Fig. 6. Transmission electron micrographs (A and B, $\times 15,000$; and $\mathbf{C}, \times 19,800$ ) of soybean hypocotyls infected with binucleate Rhizoctonia AG-K isolate $8-3$ and showing papillae on the inside of cortical cells walls. A and B, The papilla appeared to form with the intracellular hypha attempting to penetrate the cortical cell wall. $\mathbf{C}$, The papilla appeared to form without the intracellular hypha touching the cortical cell wall. $\mathbf{B}$ and $\mathbf{C}$, The hyphae are in intercellular spaces. EC $=$ epidermal cell, $\mathrm{CC}=$ cortical cell, IS = intercellular space, $\mathrm{H}=$ hypha, $\mathrm{P}=$ papillae, and the double arrows show the boundary between the cell walls of epidermal and cortical cells. Bar $=1.0 \mu \mathrm{m}$. 
$R$. solani alone (Fig. 8). On the side facing the BNR inoculum, there were few hyphae of $R$. solani growing over the tissue, the hyphae branched sparingly, and infection cushions were rarely observed. In addition, when examined with SEM, the hyphae that grew over the host surface did not appear attached to the host compared with hyphae on tissue not inoculated with BNR. On the tissue paper inoculum, a mass of aerial hyphae developed, which demonstrated the high inoculum potential. However, even in the presence of this large mass of hyphae, there were few hyphae growing on the side of the soybean toward the BNR inoculum. This difference in growth pattern was consistent across 56 of 60 samples examined. The four samples that did not show this difference in growth pattern did not have BNR growing out over the tissue.
Apparently, the BNR failed to grow from the inoculum. When BNR grew for $24 \mathrm{~h}$ prior to inoculation with $R$. solani, the effect on the growth pattern of $R$. solani also was apparent as reduced hyphal growth, but it was not as marked as when BNR grew for $48 \mathrm{~h}$. The observations with light microscopy were corroborated with SEM observations.

BNR isolate 8-3 alone caused no lesions, but $50 \%$ of the hypocotyls inoculated with $R$. solani alone developed lesions after $48 \mathrm{~h}$ (Fig. 9A). Only $30 \%$ of the soybeans inoculated with $R$. solani at $48 \mathrm{~h}$ after inoculation with BNR showed lesions after $48 \mathrm{~h}$ of growth of $R$. solani (Fig. 9B). This reduction in lesion formation on hypocotyls occurred when the inoculum of $R$. solani was placed on either the cotyledon side or the root side of the BNR inoculum.
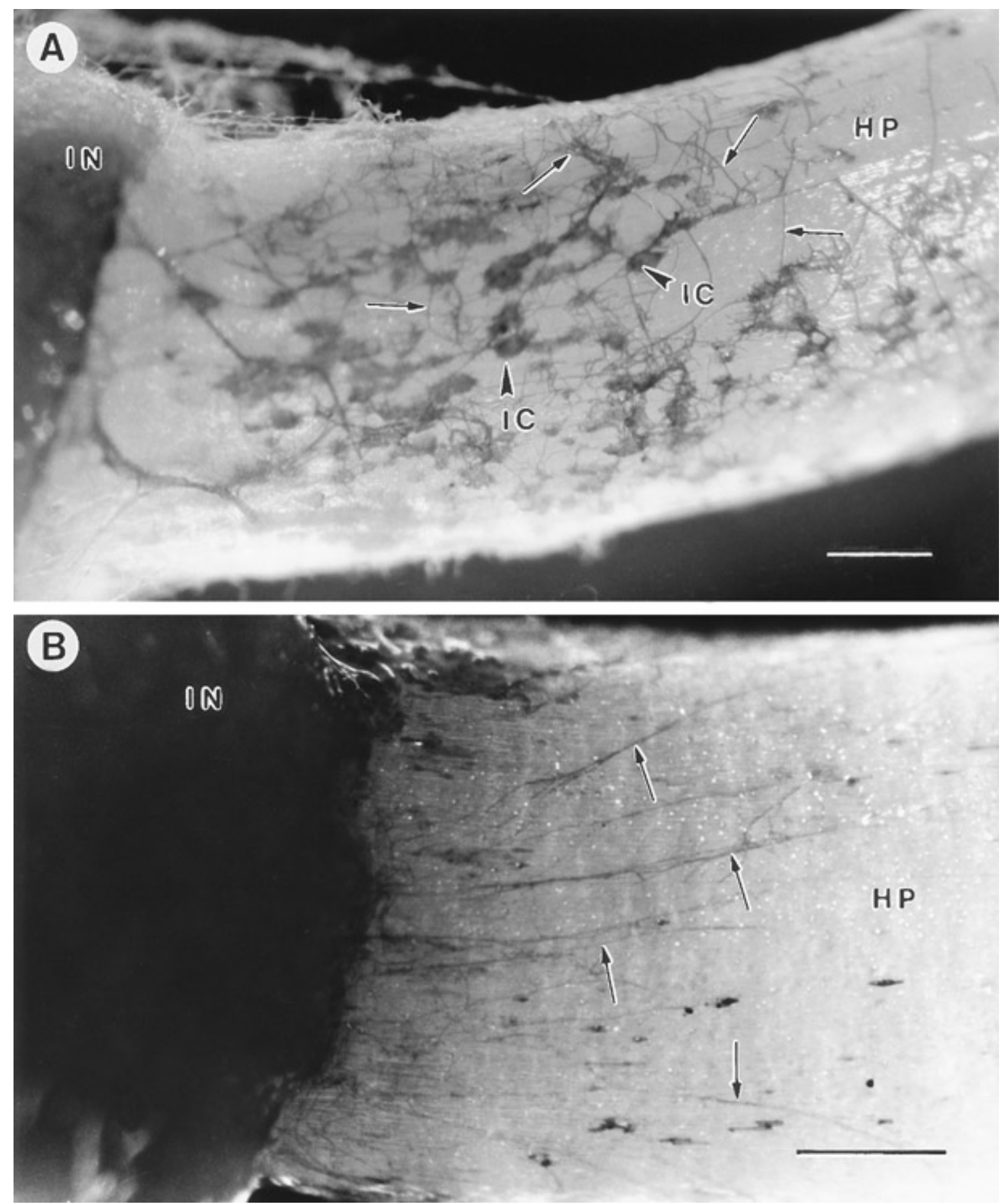

Fig. 7. Hyphae of A, Rhizoctonia solani AG-4 (×17.5) and B, binucleate Rhizoctonia AG-K isolate 8-3 (×23.7) after 24 h of growth on the surface of soybean hypocotyls. Notice the difference in the growth pattern of the hyphae (small arrows) of these two fungi. Infection cushions of $R$. solani are the dark-stained blotches on the hypocotyl. The dark material on the left side is the tissue paper inoculum. $\mathrm{HP}=$ hypocotyl, IC $=$ infection cushion, and IN $=$ inoculum. Bar $=1.0 \mathrm{~mm}$. 
Any lesions caused by $R$. solani always appeared distally, not proximally, to the BNR inoculum when the plant was inoculated with $R$. solani 24 to $48 \mathrm{~h}$ after inoculation with BNR. These lesions were very small (less than $1 \mathrm{~mm}$ in diameter), especially when hypocotyls were inoculated with $R$. solani $48 \mathrm{~h}$ after BNR. When $\mathrm{BNR}$ and $R$. solani were coinoculated at the same time, lesions formed both proximally and distally to the BNR inoculum (Fig. 9B). Those lesions were consistently larger than those on plants inoculated at 24 to $48 \mathrm{~h}$ after BNR.

Beginning about $24 \mathrm{~h}$ after coinoculation, 102 close contacts between hyphae of BNR and $R$. solani on soybean hypocotyls and roots were examined carefully over a 48 -h period. There was no evidence of antagonism, lysis, hyperparasitism, or inhibition of growth among the intermingling hyphae.

There was a significant $(P=0.05)$ reduction in the number of hyphae of $R$. solani on the surface of hypocotyls preinoculated with BNR as compared with those without BNR in all three of the experiments. At $2 \mathrm{~mm}$ from the $R$. solani inoculum, the mean numbers of hyphae on hypocotyls preinoculated with BNR were 3.1, 3.3, and 4.7, while on the hypocotyls with $R$. solani alone, the means were 6.4, 11.8, and 16.2 for the three experiments, respectively. At $4 \mathrm{~mm}$, the means were $1.4,1.0$, and 2.5 on the hypocotyls preinoculated with

TABLE 1. Effect of preinoculation with binucleate Rhizoctonia (BNR) isolate $8-3$ on soybean inoculated 24 h later with $R$. solani AG-4

\begin{tabular}{lcc}
\hline Treatment $^{\mathrm{a}}$ & No. of healthy plants & Disease severity $^{\mathrm{b}}$ \\
\hline $\mathrm{BNR}$ & 15.0 & $0.0^{\mathrm{c}}$ \\
$\mathrm{BNR}+$ R. solani at $1 \mathrm{~cm}^{\mathrm{d}}$ & 7.3 & 1.0 \\
$\mathrm{BNR}+R$. solani at $0.5 \mathrm{~cm}^{\mathrm{d}}$ & 8.0 & 1.0 \\
$\mathrm{BNR}+$ R. solani at $0 \mathrm{~cm}^{\mathrm{d}}$ & 10.3 & 0.8 \\
$R$. solani & 7.3 & 1.5 \\
LSD & 2.0 & 0.3
\end{tabular}

a The experiment was conducted three times with 15 subsamples per treatment. Data from the three separate experiments were pooled before the analysis of variance.

${ }^{\mathrm{b}}$ Disease severity based on a 0 to 5 scale in which $0=$ no disease and $5=$ hypocotyls/roots girdled or dead.

c Data from this treatment not included in the analysis of variance.

d $0,0.5$, and $1 \mathrm{~cm}$ is the distance between the BNR and $R$. solani inoculum.

e Treatment means were compared by Fisher's protected least significant difference test $(P=0.05)$.
BNR, and on hypocotyls with $R$. solani alone, the means were 3.4, 8.7, and 10.3 for the three experiments, respectively. On the hypocotyls preinoculated with BNR, the BNR hyphae were readily observed growing over the surfaces, but none reached the $4 \mathrm{~mm}$ distance from the $R$. solani inoculum before hyphal counts were conducted.

\section{DISCUSSION}

The evidence that hyphae of BNR appeared attached to the epidermis of hypocotyls and roots of soybean suggested there were compatible interactions between hyphae and host prior to infection. Attachment of inoculum appears to be a prerequisite for the infection process by fungi $(17,23,31,42)$ and may be required for a recognition of the host and for fungal development (12). The penetration pegs of BNR observed in this research originated from hyphae that appeared attached to the epidermis. In $R$. solani, penetration structures such as infection cushions, appressoria, and penetration pegs develop from flattened hyphae that are appressed to the epidermis $(9,15,26,30$, 39). The penetration pegs of BNR were slender compared with those of $R$. solani, which range from 1 to $2 \mu \mathrm{m}$ in diameter (30). This difference may be explained by the smaller-diameter hyphae of BNR.

The BNR isolates actively colonized surfaces of soybean hypocotyls and roots, but the fungus formed a rather sparse growth of hyphae over the host as compared with the netlike growth of $R$. solani. The BNR, however, only penetrated epidermal cells of the host. The rapid penetration of epidermal cells and subsequent penetrations through the radial walls, plus the rapid development of intracellular hyphae with large numbers of mitochondria, indicated highly active hyphal growth with little or no host resistance expressed in epidermal cells. There was no evidence that penetrations of epidermal cells were ever stopped by an active host response. Cardoso and Echandi (6) first reported that BNR colonized the rhizosphere, rhizoplane, and epidermal cells of bean seedlings, but did not successfully penetrate cortical cells. However, they did not characterize or photograph the infection process. Jabaji-Hare et al. (22) also observed infection of bean epidermal cells by BNR and reported that an electron-dense material, identified as pectin, was present in the epidermal cell walls of bean inoculated with BNR, but not with $R$. solani. They hypothesized that the layer of pectin acted as a protective barrier against infection by $R$. solani. We did not

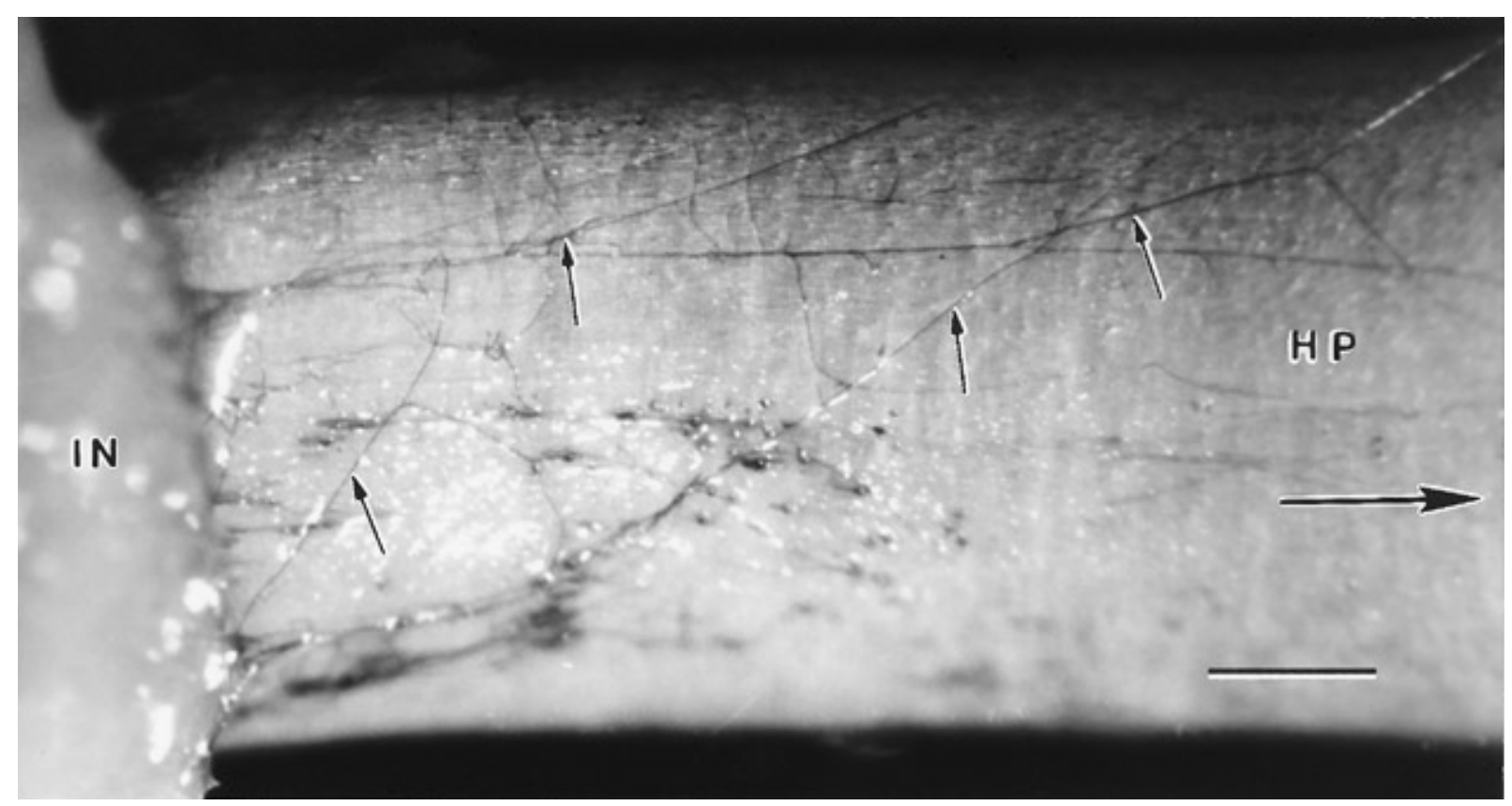

Fig. 8. Growth of Rhizoctonia solani after $48 \mathrm{~h}$ on a soybean hypocotyl (HP) that was inoculated with binucleate Rhizoctonia AG-K isolate 8-3 $48 \mathrm{~h}$ before inoculation with $R$. solani. There was $1 \mathrm{~cm}$ between inocula. The tissue paper inoculum (IN) of $R$. solani is on the left. Note the lack of hyphal growth (small arrows), branching, and infection cushions compared with Figure 7A. The large arrow points in the direction of the binucleate Rhizoctonia. There are no hyphae of the binucleate Rhizoctonia in this portion of the hypocotyl; they had not yet grown to this area. Bar $=1.0 \mathrm{~mm}$. 
detect an electron-dense material in the walls of soybean epidermal cells infected with BNR.

The degradation of the cuticle at the site of penetration by BNR suggested that penetration involved enzymatic action. The necrosis observed in epidermal and cortical cells, where there was no definitive evidence of fungal penetrations, also suggested that enzymatic action or a toxin was involved in the infection and colonization process. Enzymatic destruction of host constituents was reported for $R$. solani when epidermal cells were infected $(2,9,21,25)$. However, the invagination of the epidermal side walls at the edges of penetrations and the invagination of the plasmalemma by the developing intracellular hyphae suggested that mechanical penetra- tion may also be involved in the infection process. Mechanical pressure as a factor in penetration of bean, cotton, and tomato by $R$. solani has been reported $(7,15,25,26)$.

BNR rapidly penetrated the epidermis of soybean when compared with the 24 to $30 \mathrm{~h}$ required by $R$. solani to penetrate bean hypocotyls (25) or the 15 to $18 \mathrm{~h}$ required to penetrate cotton hypocotyls (39). $R$. solani may require a longer period to infect hosts compared with BNR because of the time required to produce the dome-shaped infection cushions before an infection peg can form. Although we did not characterize the infection process by $R$. solani on soybean, infection occurred within $48 \mathrm{~h}$, because lesions were observed within that time.
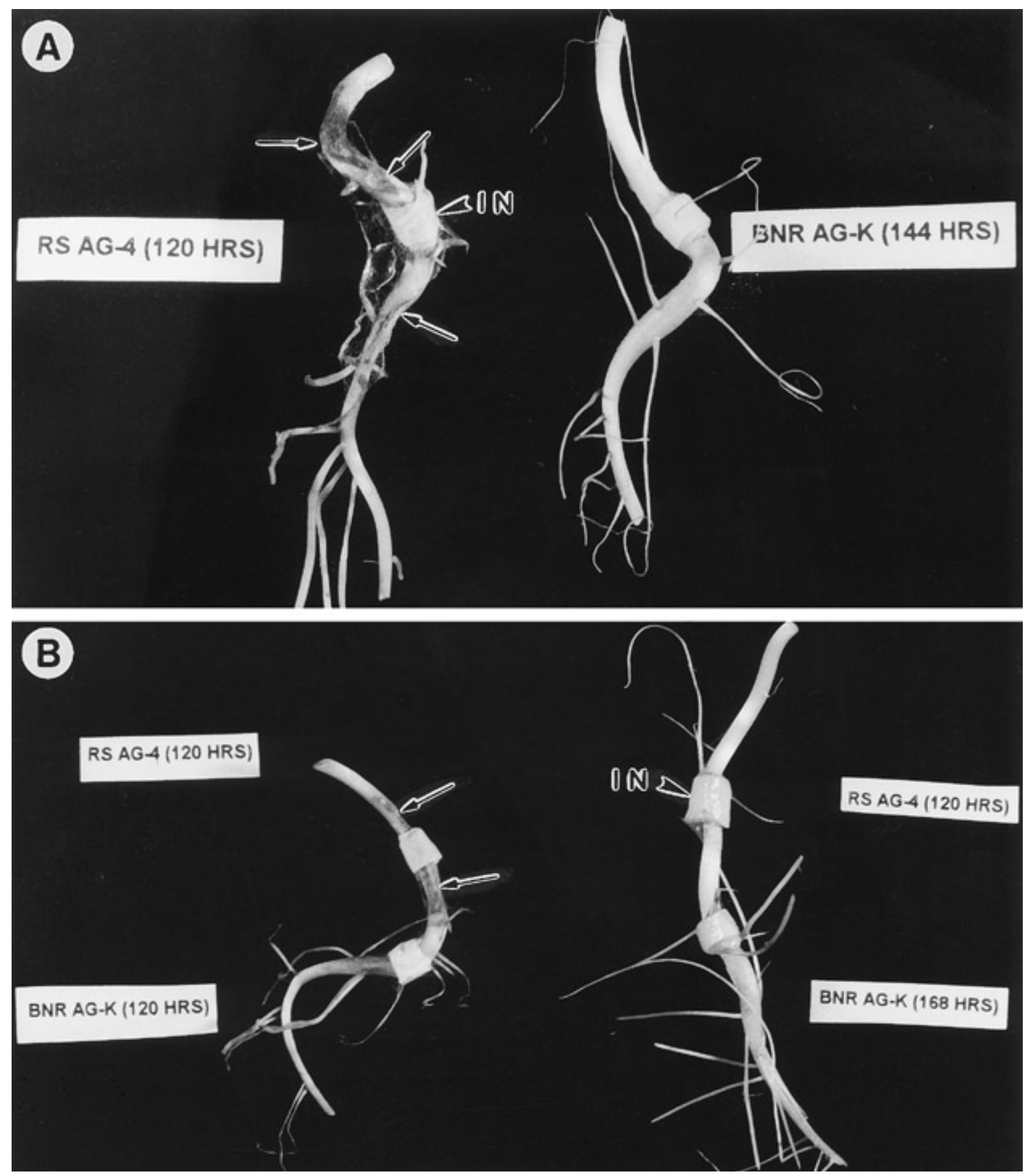

Fig. 9. Hypocotyls of soybean inoculated with Rhizoctonia solani AG-4 (RS) and binucleate Rhizoctonia AG-K isolate 8-3 (BNR). A, Hypocotyls inoculated with RS or BNR alone. Note the lesions (arrows) caused by RS and the absence of lesions on soybean inoculated only with BNR. B, Hypocotyls inoculated with both RS and BNR. On the left side, the plant was inoculated at the same time with both fungi, and lesions (arrows) developed on both sides of the RS inoculum. On the right side, the plant was inoculated with RS $48 \mathrm{~h}$ after inoculation with BNR. Preinoculation with BNR protected the plant from lesion development by RS. The tags refers to the inoculum (IN), and the time in parentheses is the hours following inoculation. 
When BNR was inoculated onto soybean prior to $R$. solani, there was a significant reduction in disease severity, even when BNR had grown for only $24 \mathrm{~h}$. Khan (27) also saw a reduction in disease severity in the greenhouse and field using the same pathogen and biocontrol agent. Protection from $R$. solani by BNR isolate 8-3 varied depending on how far the $R$. solani was placed from BNR. The shorter the distance, the greater the protection; the greatest protection occurred when $R$. solani was placed directly next to the BNR. BNR grew less than $0.5 \mathrm{~cm}$ in the first $24 \mathrm{~h}$ following inoculation; therefore, at greater distances between $R$. solani and BNR, there would be a reduced effect of biocontrol, because BNR would not be infecting epidermal cells in those areas. The timing of inoculation also was important. There were fewer hyphae of $R$. solani on soybean tissue when inoculation occurred $48 \mathrm{~h}$ after placement of BNR compared with inoculation at $24 \mathrm{~h}$. Furthermore, when soybean was inoculated with $R$. solani $48 \mathrm{~h}$ after BNR ( $1 \mathrm{~cm}$ apart), the lesions were very small or not formed at all, while inoculations at the same time resulted in large lesions (Fig. 9). Villajuan-Abgona et al. (36) found that applying BNR at the same time as $R$. solani AG-4 failed to provide protection to cucumber seedlings, but preinoculation of hypocotyls with BNR for $24 \mathrm{~h}$ or more gave protection in the greenhouse for at least 14 days after inoculation with $R$. solani.

The change in the growth pattern of $R$. solani on soybean preinoculated with BNR compared with $R$. solani alone consisted of a reduction in hyphal growth, branching, and infection cushions. These changes occurred on the tissue when there was no intermingling of BNR and $R$. solani hyphae. These observations, plus the evidence that BNR infects host epidermal cells, suggests that the mechanism of biocontrol on soybean is induced resistance (35). Also, lesions caused by $R$. solani always formed distally, never proximally, to the BNR, indicating a host response that was greater toward the area with BNR and diminishing as the distance from BNR increased. The reduction in growth of $R$. solani on the soybean tissue inoculated with BNR indicates that host substances may be released that inhibit the growth of $R$. solani on the host surface. This could also affect the formation of infection cushions of $R$. solani, because host exudates are thought to be important factors in their formation $(9,10,11,16,28)$. Marshall and Rush (29) found a positive correlation between disease severity in rice and formation of infection cushions by $R$. solani and $R$. oryzae. In addition, hyphae of $R$. solani grown on BNR-inoculated soybean did not appear attached to the host surface as they did on noninoculated host tissue. This suggests that host recognition by $R$. solani was perturbed by prior inoculation with BNR. Induced resistance in soybean initiated by fungi has been reported (40).

The formation of papillae during the attempted penetrations of cortical cells by BNR was further evidence for induced resistance as the mechanism of biocontrol. As a defense mechanism against BNR, papillae may also protect soybean cortical cells from other fungi such as $R$. solani. However, the infection of soybean by $R$. solani after colonization by BNR was not investigated; therefore, the role papillae play in preventing infection of cortical cells by $R$. solani is unknown.

Papillae formation around the sites of attempted fungal penetrations apparently is a general resistance response of plants to pathogens (1). In barley and wheat, putative guanidine compounds, polyphenolic substances, and callose found in papillae were considered to be an early resistance response in grasses resistant to Erysiphe graminis f. sp. hordei (37). Benhamou et al. (3) reported that the enzyme beta-fructosidase, which converts sucrose into glucose and fructose, accumulated in papillae and intercellular spaces when resistant plants of tomato were infected by Fusarium oxysporum. An exogenous supply of glucose and 3- $O$-methylglucose can reduce lesion development caused by $R$. solani on rice seedlings (29). It was suggested that 3-O-methylglucose inhibited formation of infection cushions of $R$. solani, while glucose suppressed pectinase (38). $R$. solani produces pectinase, which is involved in the removal of host cell wall pectin during the infection process (39).
Induced resistance is considered to be a general resistance response initiated following the inoculation with a nonpathogen or weak pathogen (35). The plant is then protected against subsequent inoculations with pathogens. One common characteristic of inducing treatments is the development of necrosis (35), as was observed in this study. In the cucumber-Colletotrichum lagenarium interaction in which induced resistance is well characterized, the resistance is expressed when the pathogen attempts to infect the host (35). In this study, we observed an effect on the pathogen, i.e., inhibition of hyphal growth, even before host penetration had started. Our observations, therefore, were similar to those of Cardoso and Echandi (6) on bean. We believe this is a novel characteristic of induced resistance that has not been studied. Whether the induced resistance we observed is systemic induced resistance (35) remains to be determined. Although induced resistance appears to be the most plausible explanations for our observations, we can not discount the possibility that infection of soybean by BNR induces fungal genes to produce compounds that adversely affect growth of $R$. solani.

Competition for infection sites has been suggested $(4,36)$ as the mechanism of biocontrol of $R$. solani by BNR. However, evidence from this research does not support competition as the primary mechanism of control on soybean. $R$. solani was unable to grow well on tissue that was close to, but not colonized by, BNR and there was also no evidence that BNR were producing an antibiotic that would inhibit growth of $R$. solani. When placed together at the same time on soybean tissue, the two fungi grew together without any evidence of interference.

BNR may be promising as biocontrol agents, because they have been shown to control root pathogens such as Rhizoctonia and Pythium ultimum on a variety of crops. A single isolate of BNR may even be able to control the same pathogen on several unrelated hosts (19). There are also reports that BNR increased dry weights of shoots and roots in the absence of pathogens $(19,36)$. A full understanding of the mechanism of biocontrol may enhance the ability to use BNR as biocontrol agents of important root diseases of crops. Extensive host-range studies are also needed to determine if BNR AG-K causes disease on specific crops, because some BNR are known to be pathogenic $(24,34)$

\section{ACKNOWLEDGMENTS}

Contribution was received from the North Dakota State University Agricultural Experiment Station, Fargo. We thank K. Iverson and S. Payne for help with the electron microscopy and photographs.

\section{LITERATURE CITED}

1. Aist, J. R. 1976. Papillae and related wound plugs of plant cells. Annu. Rev. Phytopathol. 14:145-163.

2. Bateman, D. F. 1970. Pathogenesis and disease. Pages 161-171 in: Rhizoctonia solani: Biology and Pathology. J. R. Parmeter, Jr., ed. University of California Press, Berkeley.

3. Benhamou, N., Grenier, J., and Chrispeels, M. J. 1991. Accumulation of beta-fructosidase in the cell walls of tomato roots following infection by a fungal wilt pathogen. Plant Physiol. 97:739-750.

4. Burpee, L. L., and Goulty, L. G. 1984. Suppression of brown patch disease of creeping bentgrass by isolates of nonpathogenic Rhizoctonia spp. Phytopathology 74:692-694.

5. Cardoso, J. E., and Echandi, E. 1987. Biological control of Rhizoctonia root rot of snap bean with binucleate Rhizoctonia-like fungi. Plant Dis. 71:167-170.

6. Cardoso, J. E., and Echandi, E. 1987. Nature of protection of bean seedlings from Rhizoctonia root rot by binucleate Rhizoctonia-like fungus. Phytopathology 77:1548-1551.

7. Christou, T. 1962. Penetration and host-parasite relationships of Rhizoctonia solani in the bean plant. Phytopathology 52:381-389.

8. Dhingra, O. D., and Sinclair, J. B. 1995. Basic Plant Pathology Methods, 2nd ed. CRC Press, Inc., Boca Raton, FL.

9. Dodman, R. L., Barker, K. R., and Walker, J. C. 1968. A detailed study of the different modes of penetration by Rhizoctonia solani. Phytopathology 58:1271-1276. 
10. Dodman, R. L., and Flence, N. T. 1970. The mechanism and physiology of plant penetration by Rhizoctonia solani. Pages 149-160 in: Rhizoctonia solani: Biology and Pathology. J. R. Parmeter, Jr., ed. University of California Press, Berkeley.

11. Downer, A. J., and Armentrout, V. N. 1983. The effect of host exudates on infection cushion morphogenesis of Rhizoctonia solani. (Abstr.) Phytopathology 73:958.

12. Epstein, L., Laccetti, L. B., Staples, R. C., and Hoch, H. C. 1987. Cellsubstratum adhesive protein involved in surface contact response of the bean rust fungus. Physiol. Mol. Plant Pathol. 30:373-388.

13. Escande, A. R., and Echandi, E. 1991. Effect of growth media, storage environment, soil temperature and delivery to soil on binucleate Rhizoctonia AG-G for protection of potato from Rhizoctonia canker. Plant Pathol. 40:190-196.

14. Escande, A. R., and Echandi, E. 1991. Protection of potato from Rhizoctonia canker with binucleate Rhizoctonia fungi. Plant Pathol. 40:197-202.

15. Flentje, N. T. 1957. Studies on Pellicularia filamentosa (Pat) Rogers. III. Host penetration and resistance, and strain specialization. Trans. Br. Mycol. Soc. 40:322-336.

16. Flentje, N. T., Dodman, R. L., and Kerr, A. 1963. The mechanism of host penetration by Thanatephorus cucumeris. Aust. J. Biol. Sci. 16:784-799.

17. Flentje, N. T., Stretton, H. M., and McKenzie, A. R. 1967. Mutation in Thanatephorus cucumeris. Aust. J. Biol. Sci. 20:1173-1180.

18. Hare, S. J., Masilamany, P., and Charest, P. M. 1994. Increased peroxidase activity in bean seedlings protected from Rhizoctonia solani infection with non-pathogenic binucleate Rhizoctonia species. (Abstr.) Phytopathology 84:1083.

19. Harris, A. R., Schisler, D. A., and Ryder, M. H. 1993. Binucleate Rhizoctonia isolates control damping-off caused by Pythium ultimum var. sporangiiferum and promote growth in Capsicum and Celosia seedlings in pasteurized potting medium. Soil Biol. Biochem. 25:909-914.

20. Herr, L. J. 1995. Biocontrol of Rhizoctonia solani by binucleate Rhizoctonia spp. and hypovirulent $R$. solani agents. Crop Prot. 14:179-186.

21. Isaac, P. K. 1964. Metabolic specialization in the mycelium of Rhizoctonia solani Kuhn. Can. J. Microbiol. 10:621-623.

22. Jabaji-Hare, S. H., Chamberland, H., Charest, P. M., and Echandi, E. 1994. Cell wall alterations in bean seedlings protected from Rhizoctonia root rot by binucleate Rhizoctonia species. Page 288 in: Abstr. Book Proc. Int. Congr. Plant Pathol., 6th.

23. Jones, J. M., and Epstein, L. 1989. Adhesion of Nectria haematococca macroconidia. Physiol. Mol. Plant Pathol. 35:453-461.

24. Kataria, H. R., and Hoffman, G. M. 1984. A critical review of plant pathogenic species of Ceratobasidium Rogers. J. Plant Dis. Prot. 95:81-107.

25. Kenning, L. A., and Hanchey, P. 1980. Ultrastructure of lesion formation in Rhizoctonia-infected bean hypocotyls. Phytopathology 70:998-1004.

26. Khadga, B. B., Sinclair, J. B., and Exner, B. B. 1963. Infection of seedling cotton hypocotyl by an isolate of Rhizoctonia solani. Phytopathol- ogy 53:1331-1336.

27. Khan, F. U. 1993. Biocontrol of $R$. solani on soybean with binucleate Rhizoctonia. Ph.D. dissertation. North Dakota State University, Fargo.

28. Marshall, D. S., and Rush, M. C. 1980. Relation between infection by Rhizoctonia solani and $R$. oryzae and disease severity in rice. Phytopathology 70:941-946.

29. Marshall, D. S., and Rush, M. C. 1980. Infection cushion formation on rice sheaths by Rhizoctonia solani. Phytopathology 70:947-950.

30. Matsuura, K. 1986. Scanning electron microscopy of the infection process of Rhizoctonia solani in leaf sheaths of rice plants. Phytopathology 76:811-814.

31. Mercure, E. M., Kunoh, H., and Nicholson, R. L. 1994. Adhesion of Colletotrichum graminicola conidia to corn leaves: A requirement for disease development. Physiol. Mol. Plant Pathol. 45:407-420.

32. Nelson, B., Helms, T., Christianson, T., and Kural, I. 1996. Characterization and pathogenicity of Rhizoctonia from soybean. Plant Dis. 80:74-80.

33. Nelson, B. D., and Kural, I. 1990. Cryogenic preservation of Rhizoctonia cultures. (Abstr.) Phytopathology 80:1042-1043.

34. Sneh, B., Burpee, L., and Ogoshi, A. 1991. Identification of Rhizoctonia species. The American Phytopathological Society, St. Paul, MN.

35. Sticher, L., Mauch-Mani, B., and Metraux, J. P. 1997. Systemic acquired resistance. Annu. Rev. Phytopathol. 35:235-237.

36. Villajuan-Abgona, R., Kageyama, K., and Hyakumachi, M. 1996. Biocontrol of Rhizoctonia damping-off by non-pathogenic binucleate $R h i$ zoctonia. Eur. J. Plant Pathol. 102:227-235.

37. Wei, Y. D., de Neergard, E., Thordal-Christensen, H., Collinge, D. B., and Smedegaard-Peterson, V. 1994. Accumulation of a putative guanidine compound in relation to other early defense reactions in epidermal cells of barley and wheat exhibiting resistance to Erysiphe graminis f. sp. hordei. Physiol. Mol. Plant Pathol. 45:469-484.

38. Weinhold, A. R., and Bowman, T. 1974. Repression of virulence in Rhizoctonia solani by glucose and 3-O-methyl glucose. Phytopathology 64 : 985-990.

39. Weinhold, A. R., and Motta, J. 1973. Initial host responses in cotton to infection by Rhizoctonia solani. Phytopathology 63:157-162.

40. Wrather, J. A., and Elrod, J. M. 1990. Apparent systemic effect of Colletotrichum truncatum and $C$. lagenarium on the interaction between soybean and C. truncatum. Phytopathology 80:472-474.

41. Xue, L., Brisson, L., and Jabaji-Hare, S. H. 1997. Activation of defense mechanisms in bean seedlings protected by non-pathogenic Rhizoctonia solani. (Abstr.) Phytopathology 87:S106.

42. Young, D. H., and Kauss, H. 1984. Adhesion of Colletotrichum lindemuthianum spores to Phaseolus vulgaris hypocotyls and to polystyrene. Appl. Environ. Microbiol. 47:616-619.

43. Yuen, G. Y., Craig, M. L., and Giesler, L. J. 1994. Biological control of Rhizoctonia solani on tall fescue using fungal antagonists. Plant Dis. 78: 118-123. 